\title{
Total serum IgE and outcome in infants with recurrent wheezing
}

\author{
F Rusconi, M F Patria, G U Cislaghi, S Sideri, L Gagliardi
}

\begin{abstract}
Objective-To investigate the relation between total serum IgE at $0.5-3$ and 3-6 years, and the risk of allergic sensitisation and persistent wheezing up to 8 years of age.

Methods-Prospective follow up study of 45 infants with highly recurrent wheezing, no allergic symptoms, and negative skin tests.

Results-In the last follow up year, 15 children still suffered from wheezing. Five wheeze-free and four episodically wheezing children had become sensitised. No association was found between early (0.5-3 years) $\operatorname{IgE} z$ scores and the recurrence of wheezing during follow up, or atopic sensitisation. IgE $z$ scores at 3-6 years were significantly higher in children with positive skin tests $(p=0.013)$, but were still not associated with recurrence of wheezing.

Conclusions-In subjects with frequent early wheezing and no signs of atopy, early total serum IgE measurements are not predictive of outcome.

(Arch Dis Child 2001;85:23-25)
\end{abstract}

Keywords: IgE; wheezing; childhood asthma

A close association between total serum $\operatorname{IgE}$ levels and the prevalence of asthma, independent of specific reactivity to allergens, has been reported in cross sectional population studies in children and adults. ${ }^{12}$ A prospective population study has also shown that children with early sensitisation and persistent wheezing had high IgE levels throughout childhood. ${ }^{3}$

The purpose of our study was to investigate the relation between total serum $\operatorname{IgE}$ and the risk of persistent wheezing and allergic sensitisation in a hospital based cohort of infants with highly recurrent wheezing and no signs of atopy. Although most wheezing infants outgrow their symptoms by school age, patients seen in asthma clinics have significantly worse outcomes than are found in longitudinal studies of the general population, reflecting the more severe asthma in children referred to hospital. From a practical point of view, it would therefore be useful to know if serum $\operatorname{IgE}$ could predict which children are at risk of more severe disease.

\section{Methods}

STUDY SUBJECTS

Fifty eight infants, born at full term and aged between 9 months and 2 years (median age 1.6 years), who attended the asthma clinic between
January 1990 and December 1991 were enrolled in the study. The inclusion criteria were a history of wheezing triggered by infections (fever and/or rhinitis); at least five wheezing attacks during the first two years of life; no history of atopic disease (eczema, urticaria, rhinoconjunctival symptoms apart from colds, shortness of breath with pollens, animals, or house dust); and negative skin tests for egg, milk, wheat, cat and dog dander, and the most common aeroallergens.

STUDY DESIGN

The children were followed up prospectively until 8 years of age. Skin tests were performed once a year; serum IgE concenterations were determined twice (four weeks or more after an acute respiratory illness), between the ages of 0.5 and 3 years, and between 3 and 6 years.

\section{PROCEDURES}

Skin prick tests were considered positive in the presence of a wheal of $\geqslant 3 \mathrm{~mm}$ in diameter and in the absence of a reaction to the control solution. Serum IgE levels were determined using the CAP system IgE FEIA (Pharmacia, Uppsala, Sweden) and log transformed for statistical analysis. An age related $\operatorname{IgE} \mathrm{z}$ score was calculated, using Kjellmann's age related values after $\log$ transformation. ${ }^{4}$

\section{Results}

Thirteen subjects were lost to follow up (nine because of a change of address and four because their parents refused further clinical evaluation).

During their first 3 years of life, the 45 children studied experienced a median of 10 (range 5 to 34) wheezing episodes, which tended to decrease between the ages of 3 and 8 years (median 6; range 0 to 26). During the last follow up year, 15 children were still experiencing episodic wheezing, four of whom also had wheezing symptoms between the attacks. Sensitisation to at least one aeroallergen was observed in nine children between the ages of 5 and 8 years; five had stopped wheezing and four still experienced episodic wheezing in the last year of follow up.

The mean (SD) IgE $\mathrm{z}$ score decreased significantly ( $\mathrm{p}=0.0002$, paired $t$ test) from 2.63 (1.53) during the first 3 years of life to 2.02 (1.17) between 3 and 6 years. The mean $\operatorname{IgE} \mathrm{z}$ score at $0.5-3$ years was not significantly different in the children with positive or negative skin prick tests, but at 3-6 years it was higher $(p=0.013)$ in the children with positive skin prick tests.

No association was found between the $\operatorname{IgE} z$ scores at $0.5-3$ or 3-6 years and the number of 


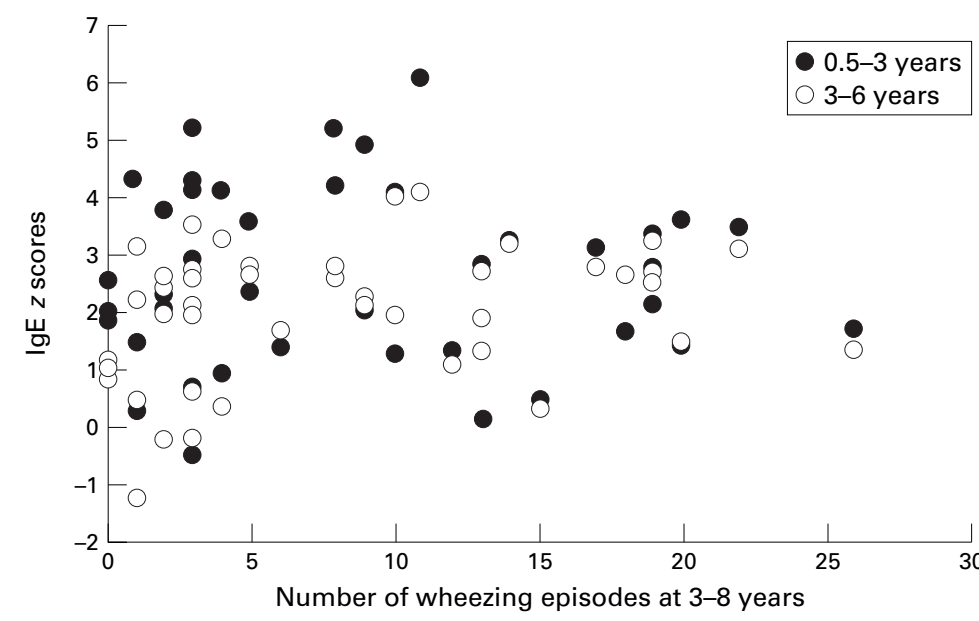

Figure 1 Number of wheezing episodes $v$ IgE $Z$ scores at 0.5-3 and 3-6 years of age.

wheezing episodes at 3-8 years of life (fig 1; $\mathrm{p}=0.93$ and $\mathrm{p}=0.14$ ), or the presence of wheezing during the last year of follow up $(\mathrm{p}=0.90$ and $\mathrm{p}=0.21)$.

\section{Discussion}

In infants with highly recurrent infection triggered wheezing, no allergic symptoms, and negative skin tests, there was no relation between early (0.5-3 years) total serum IgE and the recurrence of wheezing up to 8 years of age or allergic sensitisation. The fact that $\operatorname{IgE}$ levels at 3-6 years of life were higher in sensitised children is clinically irrelevant because sensitisation did not seem to be an important risk factor for wheezing; in fact five of nine sensitised children had stopped wheezing in the last year of follow up. The major determinant of asthma in these children might be a congenital impairment in airway function. In severely affected subjects chronic airway inflammation probably further maintains the disease.

Increased total serum IgE has been observed in association with acute viral infections in both atopic and non-atopic individuals. ${ }^{5}$ Although we measured serum IgE at least four weeks after an acute infection leading to wheezing, we cannot exclude the possibility that viral exposure may have provoked an abnormal IgE response in our patients. It has also been suggested that production of IgE not driven by specific allergens could be a consequence of the inflammatory process in the asthmatic airways. ${ }^{6}$

\section{CONCLUSIONS}

Our study suggests that in infants with frequent wheezing and no signs of atopy measurement of total serum IgE will not help predict which subjects are either at risk for recurrent or persistent wheezing symptoms or atopic sensitisation by school age.

1 Burrows B, Martinez FD, Halonen M, et al. Association of asthma with serum IgE levels and skin-test reactivity to allergens. N Engl f Med 1989;320:271-7.

2 Sunyer J, Antó JM, Castellsagué J, et al, and the Spanish Sunyer J, Anto JM, Castellsague J, et al, and the Spanish
Group of the European Study of Asthma. Total serum IgE Group of the European Study of Asthma. Total serum IgE
is associated with asthma independently of specific IgE levels. Eur Respir f 1996;9:1880-4.
3 Sherril DL, Stein R, Halonen M, et al. Total serum IgE and its association with asthma symptoms and allergic sensiti$28-36$.

4 Kjellman N-IM, Johansson SGO, Roth A. Serum IgE levels in healthy children quantified by a sandwich technique (PRIST). Clin Allergy 1976;6:51-9.

5 Perelmutter L, Potvin L, Phipps P. Immunoglobulin E response during viral infections. F Allergy Clin Immunol 1979;64:127-30

6 Burrows B, Martinez F, Cline MG, et al. The relationship between parental and children's serum IgE and asthma. Am $\mathcal{F}$ Respir Crit Care Med 1995;152:1497-500.

\section{Commentary}

The differential diagnosis of wheeze in childhood has always been difficult, and in the past various ill defined syndromes were recognised and distinguished from asthma, including asthmatic bronchitis and wheezy bronchitis. Thus in a general practice survey conducted in 1958, Logan and Cushion ${ }^{1}$ reported an annual consultation rate for asthma of $0.9 \%$ of children, with a male to female ratio of $2: 1$, compared with consultation rates for bronchitis of $6.9 \%$ of children, in whom the sex ratio was 1.1:1. These sex differences suggested that bronchitis and asthma might be different disorders, but in an influential paper from Melbourne, Howard Williams and his colleagues concluded that, at least epidemiologically, wheezy bronchitis could not be distinguished from asthma. ${ }^{2}$ Following the publication of this paper, it gradually became established practice to diagnose asthma in the great majority of children with recurrent wheeze, and at least some of the recent increase in asthma has been the result of such changes in diagnostic labelling. ${ }^{34}$

Diagnostic lumping is of course easier than splitting, especially in the absence of satisfactory definitions to permit accurate splitting, and has the potential advantage of ensuring that underdiagnosis is not followed by undertreatment. ${ }^{5}$ However, it soon became apparent that in early childhood lumping was creating new problems. Many patients were receiving inappropriate (and ineffective ${ }^{6}$ ) asthma treatment for virus associated wheeze, a transient problem that is generally gone by school age. Calls for a change in terminology ${ }^{7}$ have not so far borne much fruit, although there has been some transatlantic support for revisiting the traditional diagnosis of wheezy bronchitis. ${ }^{8}$

It is difficult to make a firm diagnosis in children who wheeze in association with upper respiratory tract infection. If asthma is defined as reversible airways obstruction, then those children who wheeze with infection and are apparently normal between attacks fit this bill. On the other hand, if asthma is defined as allergic airways disease, then few such children have any evidence of allergy and would not be considered to be asthmatic. The situation is further confused by the fact that upper respiratory tract infection is the most important trigger for wheeze in children with asthma. ${ }^{9}$ Nevertheless, the case for distinguishing virus associated wheeze from asthma is becoming increasingly strong.

In a group of children who had been admitted to hospital before the age of 2 years with an acute wheezing episode, and followed up to around the age of 5 years, Wilson et al found that 
bronchial responsiveness and illness severity were related to a family history of asthma but not to the results of skin prick testing or serum IgE. ${ }^{10}$ In other words, early onset wheeze appeared to be a different condition from classical atopic asthma. The mechanism of vims associated wheeze is uncertain, but may reflect a congenital diminution of airway size. ${ }^{11}$ What is increasingly clear is that virus associated wheeze is not a precursor of asthma in later childhood. ${ }^{12}$

Rusconi et al's paper describes 45 children with recurrent wheeze associated with infections in the first 2 years of life who were followed until the age of 8 years. The wheeze tended to diminish (and in two thirds it disappeared) during the follow up period, and the course of the illness was unrelated to IgE concentration either at 0.5 to 3 years of age, or at 3 to 6 years. These findings add further support to the view that virus associated wheeze in early childhood is not related to atopy.

Perhaps it $i$ time for a change of name.

GEORGE RUSSELL

Department of Child Health, University of Aberdeen, Aberdeen AB25 2ZD, UK
1 Logan WPD, Cushion AA. Morbidity statistics from general practice 14. General Register Office, Studies on Medical and Population Subjects. London: HMSO, 1958.

2 Williams H, McNicol KN. Prevalence, natural history, and relationship of wheezy bronchitis and asthma in children. An epidemiological study. BMF 1969;iv:321-5.

3 Hill R, Williams J, Tattersfield A, et al. Change in use of asthma as a diagnostic label for wheezing illness in schoolchildren. BMF 1989;299:898.

4 Omran M, Russell G. Continuing increase in respiratory symptoms and atopy in Aberdeen schoolchildren. BMF 1996;312:34

5 Speight AN, Lee DA, Hey EN. Underdiagnosis and undertreatment of asthma in childhood. BMF 1983;286:1253-6.

6 Wilson N, Sloper K, Silverman M. Effect of continuous treatment with topical corticosteroid on episodic viral wheeze in preschool children. Arch Dis Child 1995;72:31720 .

7 Silverman M, Wilson N. Asthma B time for a change of name? Arch Dis Child 1997;77:62-4.

8 Martinez FD, Helms PJ. Types of asthma and wheezing. Eur Respir f 1998;27(suppl):3-8s.

9 Abramson MJ, Marks GB, Pattemore PK. Are nonallergenic environmental factors important in asthma? Med f Aust 1995;163:542-5.

10 Wilson NM, Dore CJ, Silverman M. Factors relating to the severity of symptoms at 5 yrs in children with severe wheeze in the first 2 yrs of life. Eur Respir $\mathcal{F} 1997 ; 10$ :34653

11 Martinez FD, Wright AL, Taussig LM, et al. Asthma and wheezing in the first six years of life. $N \mathrm{Engl} \mathcal{F} \mathrm{Med}$ 1995;332:133-8.

12 Dodge R, Martinez FD, Cline MG, et al. Early childhood respiratory symptoms and the subsequent diagnosis of asthma. F Allergy Clin Immunol 1996;98:48-54.

\section{A mother and bingo}

Nurses in Boston, Massachusetts (Neonatal Network, (Fournal of Neonatal Nursing) 2000;19:7-11) have described a mother's apparent addiction to playing bingo which interfered with her care of her children and her bonding to her newborn baby.

They list 10 signs of gambling addiction-preoccupation, increasing the dose (stake), unsuccessful attempts to stop, irritability following withdrawal from gambling, gambling to regain money lost the day before, lying about gambling, crime to fund gambling, loss of a job or close relationships, and accepting money from others because of gambling losses - and they refer to a 10 item screening tool based on similar factors. It is estimated that some $1.6 \%$ of adults in North America develop pathological gambling at some time in their lives and $30 \%$ of such gamblers are women.

Bingo is certainly popular in the UK but I haven't heard of it causing this kind of problem. Perhaps nobody has looked for it.

ARCHIVIST 